\section{TRILLIONS OF TREES}

SURVEY OF SURUEYS FINDS 422 TREES FOR EVERY PERSON ON EARTH

Three trillion: the latest estimate of the planet's
tree population, published in this issue of tree population, published in this issue of
Nature (see page 201), exceeds the number of stars in the Milky Way. At more than 7 times the impressive, but it should not necessarily be taken as good news. The forest-density study from tree counts on the ground that covered more than 4,000 square kilometres - also estimated that 15 billion trees are cut down each year. And in the 12,000 years since farming began spreading across the globe, the
number of trees on our planet has fallen by almost half.

\section{OLD ESTIMATE 400 BILILON}

\section{NEW ESTIIMATE 3.04 TRILION}

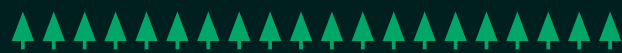

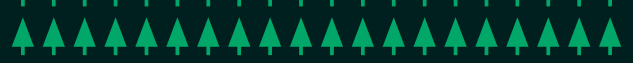
44444444444444444 4444444444444444444 4444444444444444

444444444444444444

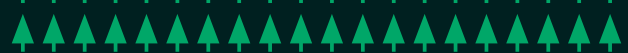

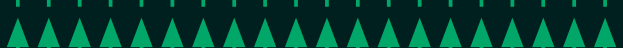
A444444444444444 44444A4A4A4444444A

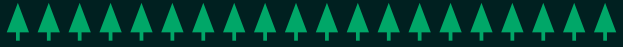
MAMALAMAMAMAMA

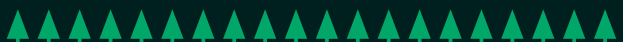
MAALAAMANAMANA

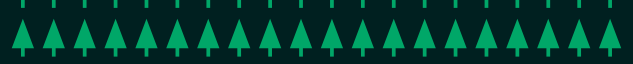
444

$\boldsymbol{A}=10$ billion trees

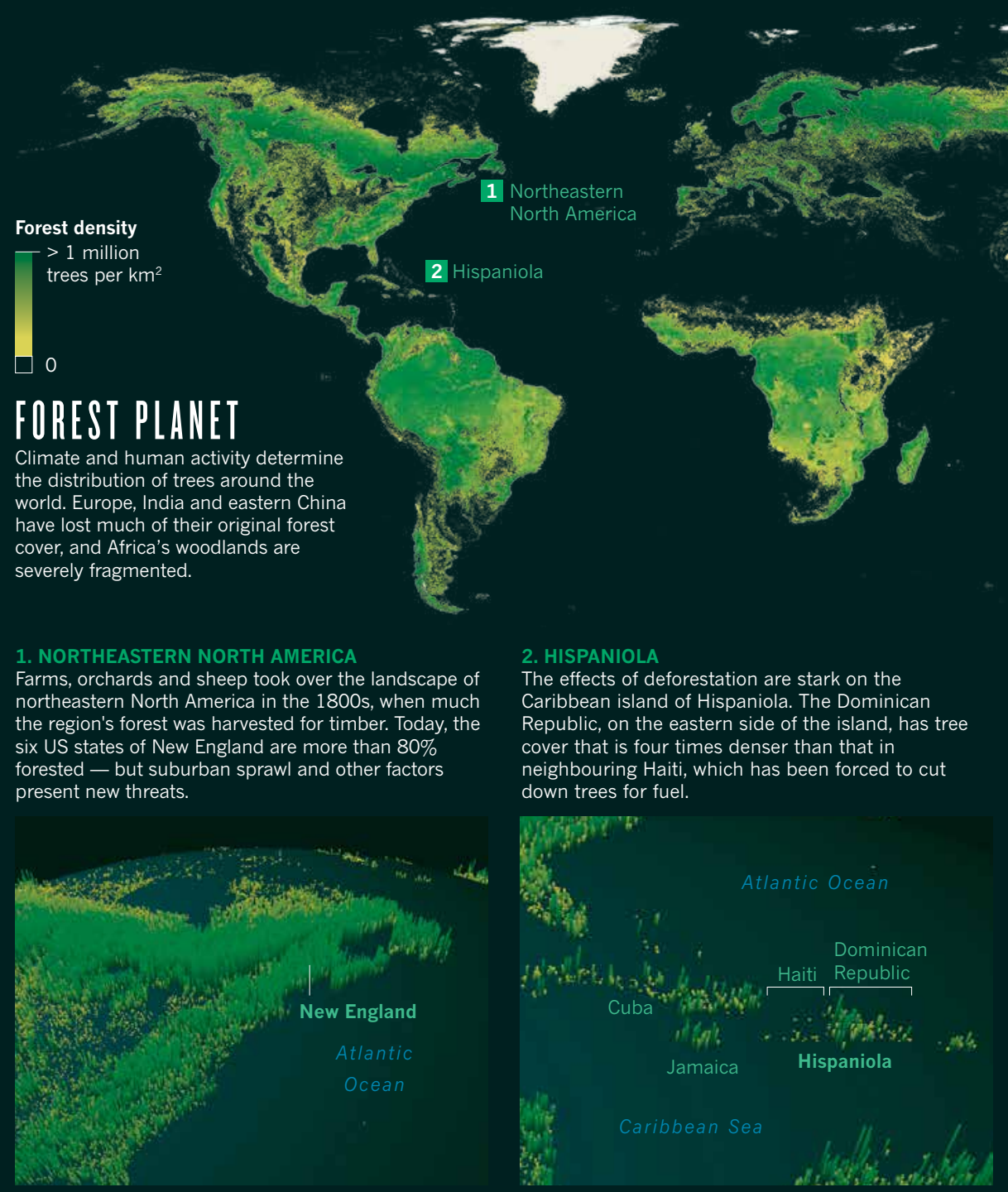

LAY OF THE LAND

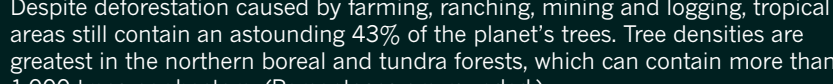

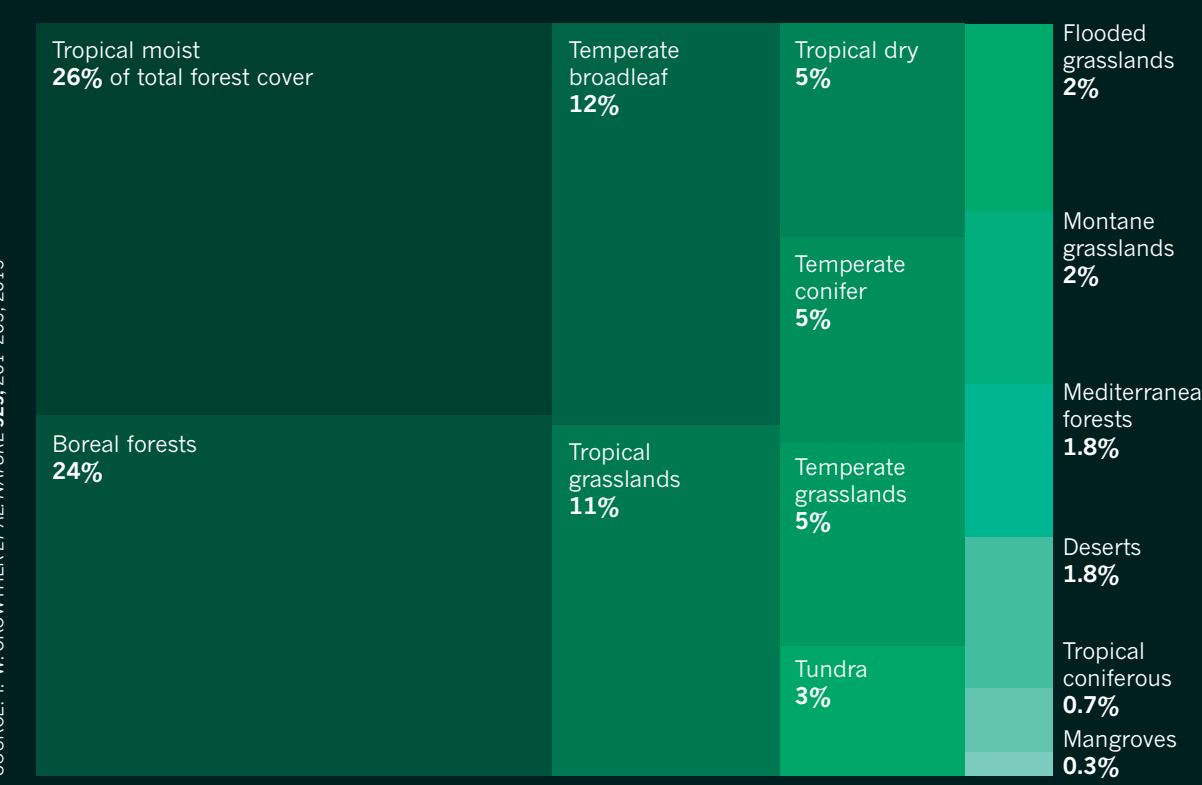

\section{LEAF OF NATIONS}

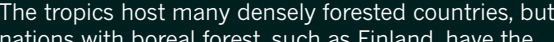
highest tree densities. At the other extreme are desert
and island nations, and some impoverished countries.

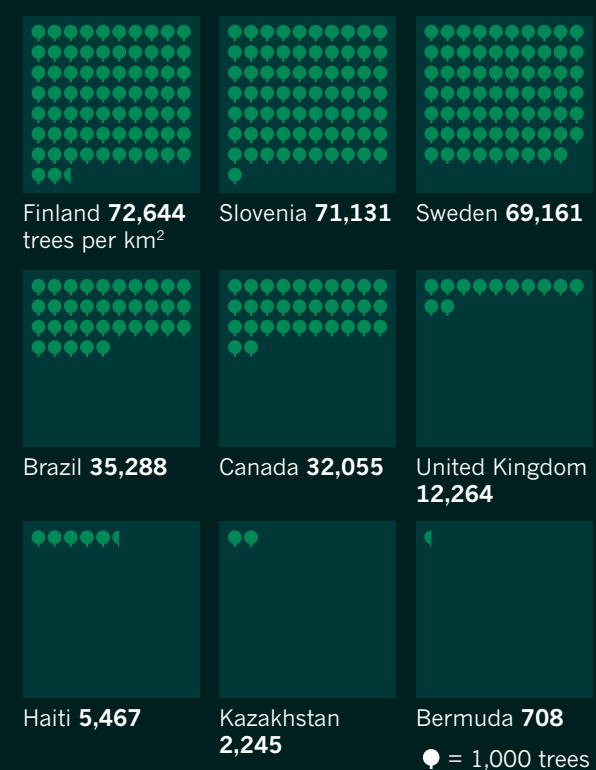

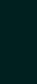

